\title{
Mine site rehabilitation conditions in Western Australia
}

\author{
ME Kragt The University of Western Australia, Australia
}

C Lison ARC Centre for Mine Site Restoration, Australia

A Manero The University of Western Australia, Australia

J Hawkins The University of Western Australia, Australia

\begin{abstract}
Rehabilitating land following mining is a major and growing issue for Western Australia (WA), with around 2.5 Mha of land currently under an active mining lease. About $85 \%$ of mining project proposals assessed by the WA Environmental Protection Authority (EPA) have had rehabilitation and/or closure conditions recommended and subsequently applied by the Minister for Environment through a ministerial statement. This is in addition to the requirements for rehabilitation and/or closure specified under the Mining Act 1978 (Government of Western Australia 1978).

This project collected and analysed publicly available information on mine rehabilitation conditions in WA to provide baseline information for the state. Closure conditions required by the EPA were assessed for 277 ministerial statements dating back to 1987. Until the 1990s, conditions related to rehabilitation have primarily been assigned to the decommissioning phase, with progressive rehabilitation requirements starting to appear from 1992 onwards. Despite the importance for assessing completion, just over 31\% of the projects specified rehabilitation targets to be met. These rehabilitation targets focussed most often on the percentage of vegetation cover and species diversity.

We further aimed to quantify the costs of rehabilitation works as part of assessing the achievability of recommended rehabilitation and/or closure conditions. However, obtaining cost data, evidence of rehabilitation progress, or evidence on rehabilitation success in publicly available documents proved challenging, with very limited amount of information available. The post-mining land use proposed at a site was not always specified and could often not be found for projects pre-2013. Current lack of transparency points at the need for knowledge sharing and/or a data repository where proponents, regulators, and researchers can jointly work towards achievable and acceptable mine rehabilitation.
\end{abstract}

Keywords: closure criteria, ecological restoration, rehabilitation, Environmental Protection Authority

\section{Introduction}

Western Australia's (WA) mineral and petroleum industry is one of the state's dominant economic sectors. In 2018, output from mining and mineral projects accounted for $72 \%$, or AU\$92 billion, of total sales value from the WA resources sector (Department of Mines, Industry Regulation \& Safety [DMIRS] 2018b). Almost AUD 18 billion was invested in WA's mining industry in 2018, representing 52\% of national Australian mining investment (DMIRS 2018a). There are currently 127 principal higher-value and export-oriented mining projects, and hundreds of quarries and smaller mines, as well as major mineral processing projects operating in all regions across the state. The vast majority of value is produced in the Pilbara region, where AUD 62.7 billion worth of iron ore sales were recorded in 2018 (DMIRS 2018a).

In 2017/2018, 44.2 Mha of land were under mining tenements, which accounts for about $17 \%$ of WA's total land area. Approximately 2.5 Mha of land are under an active mining lease (DMIRS 2018b). With vast areas of land being affected by mining and exploration, it is important that disturbed land is ultimately returned to a state that supports agreed post-mining land use/s. To achieve successful rehabilitation, objectives, closure 
criteria, or rehabilitation conditions need to be set by the proponent or the regulator. Such conditions have to be achieved before relinquishment can occur.

It is currently, however, not known what rehabilitation outcomes are envisaged for the many mining projects in WA. The DMIRS defines rehabilitation objectives as (i) safe to humans and animals; (ii) geotechnically stable; (ii) non-polluting/non-contaminating; and (iv) capable of sustaining a proposed post-mining land use without unacceptable liability to the state. The Environmental Protection Authority (EPA) further aims for rehabilitation to be undertaken in an ecologically sustainable manner that supports agreed outcomes and land uses (Department of Mines \& Petroleum [DMP] \& EPA 2015). In this project, we investigate what rehabilitation conditions are required of mining projects in WA, evaluate what rehabilitation targets are set by the regulator, and assess whether these conditions vary over time, across regions, or between resources.

\subsection{Regulatory context in Western Australia}

The key regulators involved with WA mine rehabilitation are the DMIRS (previously known as the Department of Mines and Petroleum) and the EPA. The DMIRS is the lead decision maker for mining projects that fall under the Mining Act 1978 (Mining Act) (Government of Western Australia 1978). Amendments to the Mining Act, which came into effect on 1 July 2011, require proponents to submit a mine closure plan to DMIRS for assessment and approval as part of mining proposal applications. The joint DMIRS/EPA Guidelines for Preparing Mine Closure Plans published in 2011 (revised in 2015) stipulate how such plans are to be prepared (DMP \& EPA 2015). An approved mine closure plan must be reviewed and resubmitted for assessment every three years after its initial approval. Mining operations and projects approved prior to 2011 and before the release of the Guidelines for Preparing Mine Closure Plans are now required to prepare mine closure plans.

The EPA conducts environmental impact assessments for any proposals resulting in significant impacts in accordance with Part IV of the Environmental Protection Act 1986 (EP Act) (Government of Western Australia 1986). DMIRS is required to refer any mining proposals that appear to be significant to the EPA for assessment. Proponents may also choose to refer a proposal directly to the EPA (DMP \& EPA 2015). The EPA further assesses mine closure under Part IV of the EP Act for projects that are not subject to the Mining Act, or when the EPA determines, as part of its environmental impact assessment, that rehabilitation and closure is a key integrating factor of a proposal or project (EPA 2018a). For any projects where rehabilitation and closure is regulated under Part IV of the EP Act, the EPA can require proponents to meet the rehabilitation and closure conditions specified in the ministerial statement (MS).

Some operations do not fall under the Mining Act and are not regulated under the EP Act. These operators are expected to liaise with relevant regulators, such as the Department of Jobs, Tourism, Science and Innovation, which manages state agreements, about their requirements for mine closure planning.

\subsection{Study objectives}

The project described in this paper assesses the state of rehabilitation conditions in WA. Knowing what is defined as rehabilitation objectives for different projects is important as this provides the basis for evaluating successful rehabilitation and, ultimately, mine closure. Our research responded to a request from the EPA and will thus focus on rehabilitation and closure conditions that are recommended by the EPA as captured in the MS (Section 1.1). In particular, we consider conditions that target flora and vegetation, fauna, and terrestrial environmental quality (land factors of the EPA) (EPA 2018b).

The overall objectives of this project are to:

1. Collect publicly available information about rehabilitation and/or closure conditions recommended by the EPA.

2. Assess whether recommended rehabilitation and/or closure conditions vary between regions or have changed over time.

3. Collate publicly available information about the progress of rehabilitation towards objectives. 


\section{Methodology}

The initial data source for this research were the MSs related to mineral and mining resource project developments that are publicly available on the EPA's webpage (EPA n.d.). These MSs were read to see what rehabilitation conditions have been imposed on each project. The focus of this study was on conditions specifically related to rehabilitation of flora or vegetation. Other data that was extracted is summarised in Table 1. All data were entered into an Excel database. Due to the variability in rehabilitation conditions, any condition/s recommended by the EPA were manually entered ad verbatim into the database.

Each rehabilitation condition was classified independently by two members of the research team into one of 17 categories (Table 2). These categories were then reviewed to ensure that they capture the primary intent of each condition. The data were then examined via pivot tables in Excel to assess:

- What rehabilitation and/or closure conditions are recommended.

- Changes in rehabilitation conditions over time.

- Differences in rehabilitation conditions between resource types and/or regions.

- Specifications of condition quantitative or qualitative targets.

- Specifications of post-mine land use.

Table 1 Data collected from resource projects' ministerial statements

\begin{tabular}{|c|c|}
\hline Variable & Description \\
\hline Number & Number of the ministerial statement (MS) \\
\hline Date & Date the MS was approved \\
\hline Project title & Description of project on the MS \\
\hline Proponent name & Proponent's name on the MS \\
\hline Project type & $\begin{array}{l}\text { Type of development approved (gas production, infrastructure, } \\
\text { mining, oilfield, etc.) }\end{array}$ \\
\hline Resource type & $\begin{array}{l}\text { Type of resource proposed to be mined at the project (bauxite, iron } \\
\text { ore, gas, limestone, sand, etc.) }\end{array}$ \\
\hline Region & $\begin{array}{l}\text { Region in which the project is located (based on the regions used by } \\
\text { the Western Australia Department of Primary Industries and } \\
\text { Regional Development) }\end{array}$ \\
\hline $\begin{array}{l}\text { Rehabilitation } \\
\text { condition text }\end{array}$ & Rehabilitation conditions imposed on the project (if specified) \\
\hline $\begin{array}{l}\text { Terrestrial footprint } \\
\text { cleared (ha) }\end{array}$ & Maximum clearing proposed in the MS (if specified) \\
\hline Post-mine land use & Post-mine land use proposed in the MS (if specified) \\
\hline Completion criteria & $\begin{array}{l}\text { Measurable condition targets specified in the conditions (if } \\
\text { applicable) }\end{array}$ \\
\hline
\end{tabular}




\section{$3 \quad$ Results}

In total, 277 MSs related to resource development projects were analysed, with approvals dating from October 1987 to December 2018 (i.e. spanning more than 31 years). These MSs covered all regions in WA and 24 different resource types (Appendix 1).

\subsection{Mine site rehabilitation conditions in ministerial statements}

Of the 277 mining and resource sector projects that were assessed by the EPA, 236 (85\%) have had some rehabilitation conditions recommended and subsequently applied by the Minister for Environment through a MS. With one exception in 1987, MSs before 2006 all applied a rehabilitation or closure condition/s of some kind. In recent years, especially since changes to the Mining Act requiring mine closure plans to be completed, the proportion of MSs with rehabilitation conditions has decreased considerably.

Every project has its unique set of rehabilitation conditions, which makes it difficult to quantitatively compare the conditions imposed. There is no standard terminology to define rehabilitation conditions. As such, conditions are worded differently across projects. To provide consistency in the results, descriptive data were grouped into common themes using thematic analysis-a common method in qualitative research. The 17 identified themes (Table 2) cover the main aspects of each rehabilitation condition. One MS can have multiple associated rehabilitation conditions addressing different categories.

By far the most used conditions were associated with preparing a decommissioning, closure, and/or rehabilitation plan. Typical conditions imposed included:

- Prepare and implement rehabilitation plan (used 28 times);

- Prepare and implement a decommissioning and rehabilitation plan (used 34 times); or

- Prepare and implement an Environmental Management Programme covering rehabilitation (used 25 times).

Conditions like these did not specify any condition targets or rehabilitation outcomes. The use of the 'planning' conditions showed no trend visible over time, regions, or resources until about 2013 when the planning requirement was used less often. This is probably due to the change in regulations under the Mining Act in 2011 that made mine closure plans a condition on the tenement. Mining operations not subject to the Mining Act (e.g. pre-1899 title or State Agreements) could be required to prepare a mine closure plan by the EPA as a condition of the MS. 
Table 2 Classification of rehabilitation conditions and the number of times each condition appeared in the dataset of ministerial statements

\begin{tabular}{lll}
\hline Category of rehabilitation condition & $\begin{array}{l}\text { Number of ministerial } \\
\text { statements }\end{array}$ & $\begin{array}{l}\text { Percentage of ministerial } \\
\text { statements (\%) }\end{array}$ \\
\hline Planning & 169 & 28.5 \\
Decommissioning and rehabilitation & 69 & 11.6 \\
Decommissioning & 18 & 3.0 \\
Rehabilitation (generic) & 63 & 10.6 \\
Progressive rehabilitation & 55 & 9.3 \\
Species selection & 23 & 3.9 \\
Progressive rehabilitation and species selection & 14 & 2.4 \\
Topsoil procedures & 33 & 5.6 \\
Research and development & 26 & 4.4 \\
Waste dumps, tailings, pits & 15 & 2.5 \\
Weed management & 15 & 2.5 \\
Rare and priority flora & 12 & 2.0 \\
Seeding procedures & 12 & 2.0 \\
Procedures and techniques (generic) & 12 & 2.0 \\
Landforms & 12 & 2.0 \\
Refers to DMP regulation & 5 & 0.8 \\
Dieback protocols & 3 & 0.5 \\
None specified & 38 & 6.4 \\
Total & 594 & 100 \\
\hline
\end{tabular}

From 1987 to approximately 1998, the conditions related to rehabilitation were primarily assigned to the decommissioning phase. In the first five years (1987-1991), conditions were primarily focused on decommissioning and removing of plants and installations. From 1991-1998, rehabilitation of the site and surrounded areas was added as a general requirement. Any conditions related to rehabilitation used in this period are typically quite generic without specifying objectives or targets for rehabilitation. For example:

- Commence rehabilitation (of the mined area/site) (used seven times).

- Rehabilitate disturbed land (used seven times).

Sometimes, quite generic reference would also be made to restoration techniques and seed collection procedures such as "Using the most successful vegetation techniques available" (Minister for Environment 1988), "Preserve seed and plant material for rehabilitation" (Minister for the Environment 2000a), or "Develop seed collection protocols for rehabilitation" (Minister for the Environment 2006). A total of 26 MSs in that period also specified procedures specific to the handling of topsoil. These typically required topsoil to be stripped and stockpiled or salvaged for future rehabilitation. References to topsoil handling were no longer made in the 2000s, possibly indicating that topsoil stockpiling had become common practice by then.

Specific requirements for progressive rehabilitation were employed intermittently from 1988 , but more often since about 2001 in the form of address/carry out/commence/ensure/implement progressive rehabilitation. 
From 2005 onwards, proponents were often also required to undertake (progressive) rehabilitation with species of local provenance (categorised as 'species selection' in Table 2).

Conditions specifying the need for rehabilitation research and trials were included more often from 2001 onwards. Such conditions were typically in the form of 'rehabilitation trials will be undertaken' or 'conduct research on methods of rehabilitation'.

There are few substantial differences between regions, other than those caused by evolutions of rehabilitation conditions imposed over time. Development applications in the Peel and Perth regions peaked in the 1980s and early 1990s, which means that those applications had a significantly larger number of associated 'decommissioning' conditions.

Development applications in the Pilbara region peaked during the 2005-2013 mining boom. The only difference standing out for the Pilbara is the significantly lower requirement for research and development, or rehabilitation trials, compared to other regions ( $1 \%$ of MSs for the Pilbara region, compared to a $6 \%$ average).

Conditions related to rare and priority flora were predominantly imposed on MSs for projects in the Peel and Wheatbelt regions, while dieback requirements only appeared in the Peel and southwest regions. Finally, weed management conditions were imposed more on projects in the Great Southern or southwest, reflecting the context of mining in those regions.

There were 205 MSs that specified the terrestrial footprint cleared under the project and that also had rehabilitation conditions applied. These were used to assess differences in conditions between projects of different sized footprints. The only difference between projects of different sizes were that conditions around rare and priority flora were imposed only on projects with $>500$ hectares of clearing. Larger projects are more likely to cover sensitive areas than smaller projects. However, given that not all projects defined their clearing limit in the MS, it is impossible to draw conclusive inferences about the relationship between imposed conditions and the size of a mining project.

\subsection{Condition targets (completion criteria)}

All 277 MSs were inspected for the specification of condition targets. Such targets serve as guides to develop completion criteria, which must be met if rehabilitation is to be demonstrated as being successful. Off all projects, only 87 were found to specify condition targets. Examples of condition targets include:

- Projected foliage cover values of local provenance native species is greater than $20 \%$ of the foliage cover values of reference sites.

- Average species diversity is greater than $20 \%$ of the average species diversity value of analogue sites (excluding weeds).

- Species diversity is not less than $60 \%$ of the known original species diversity.

- Priority flora are re-established with not less than $50 \%$ success after three years and $65 \%$ success after five years.

- Weed coverage is less than $10 \%$.

Although the targets varied considerably across projects, a series of common themes were identified (Table 3). Some projects have multiple targets, and some condition targets were articulated in ways that covered more than one theme. The total number of observations is therefore more than 87 .

Specifying the percentage of vegetation cover and target species diversity/composition was by far the most common target, appearing 44 times. Weed species or weed cover, is the second most recurrent target, although this was only used from 2006 onwards. Likewise, percentage cover and species diversity targets appear for the first time in 2006, prior to which vegetation targets used less concise language. In fact, targets set in the 1990s employ the terms 'vegetation' or 'native vegetation', without specifying which aspects (cover, diversity, or other) are targeted. 
Before 2009, two widely used targets were based on the loosely defined concepts of 'area' and 'rehabilitation'. 'Area' would refer to the mine footprint and the associated target will typically indicate the need to rehabilitate this footprint. For example, one statement from the year 2000 reads as follows:

"Render mine site areas safe and stable and encourage re-establishment of self-sustaining ecosystems." (Minister for the Environment 2000b)

Before 2006, 'rehabilitation' also appears frequently as an umbrella term, for example:

"The objective (of the Rehabilitation Plan) is to ensure that closure planning and rehabilitation are carried out in a coordinated, progressive manner and are integrated with development planning." (Minister for the Environment 2005)

Landforms were mentioned in eight out of 87 projects with targets, ranging from 1991 to 2012 . Other targets mentioned only three times or less include waste rock dumps, pastures, priority fauna, ponds, tailing storage facilities, soil profiles, ecosystems, and ecological functions.

Table 3 Classification of rehabilitation conditions targets and the number of times each target appeared in the dataset of ministerial statements

\begin{tabular}{ll}
\hline Category of condition target & Number of times specified \\
\hline $\begin{array}{l}\text { Percentage vegetation cover and/or } \\
\text { species diversity or composition }\end{array}$ & $44(31 \%)$ \\
Weeds & $28(20 \%)$ \\
Vegetation & $25(18 \%)$ \\
Rehabilitation & $14(10 \%)$ \\
Area targets (for & $8(5 \%)$ \\
mined/rehabilitated/disturbed land) & $8(6 \%)$ \\
Landforms & $6(4 \%)$ \\
Ecosystems & $8(6 \%)$ \\
Other & $\mathbf{1 4 1}$ \\
\hline
\end{tabular}

Interestingly, most condition targets provided an indication of the reference to be used in defining the target levels. In some cases, two or up to three references were noted. Table 4 provides a summary of the references mentioned, by frequency of appearance.

Baseline conditions (also referred to as 'pre-mining' conditions) was the most common reference, followed by 'surrounding' areas, which encompasses terms as 'nearby', 'adjacent', and 'local'. It is worth noting that 'surrounding' areas was widely used in the 1990s and 2000s. However, in 2010, the term 'undisturbed natural analogue' is introduced, which is subsequently adopted by most condition targets. Out of 14 references to 'undisturbed natural analogue', 10 are in the Pilbara region.

References to land use, such as 'post-mining land use' (PMLU) or 'designated end land use', were references in 26 cases, often without specifying the actual land use. Only in a few cases, e.g. 'Tuart forest' or 'woodland', are PMLU mentioned. The fourth most common reference is 'best-practice', although this is often undefined. A number of condition targets also make mention to setting conditions in consultation with regulators or following regulatory documents. Between 2005 and 2006, eight condition targets were found specifically referring to the Australian and New Zealand Minerals and Energy Council (ANZMEC)/Minerals Council of Australia (MCA) Strategic Framework for Mine Closure (ANZMEC \& MCA 2000). 
Table 4 Classification of references for conditions targets and the number of times each reference appeared in the dataset of ministerial statements

\begin{tabular}{ll}
\hline Reference statement & Number of times specified \\
\hline Baseline & $37(25 \%)$ \\
Surrounding areas & $36(24 \%)$ \\
Post-mine land use & $26(17 \%)$ \\
Best-practice & $17(11 \%)$ \\
Undisturbed natural analogue & $14(9 \%)$ \\
Consultation with regulator & $10(7 \%)$ \\
ANZMEC/MCA & $8(5 \%)$ \\
Designated area within the mine site & $2(1 \%)$ \\
Total & $\mathbf{1 2 8}$ \\
\hline
\end{tabular}

When examining condition targets over time, it was observed that those defined from 2006 onwards tend to be more specific in the identification of well-defined rehabilitation attributes (e.g. species diversity or vegetation cover). By contrast, until the mid-2000s, targets were often vaguely defined and based on broad terms such as 'rehabilitation' or 'mine area'. While most specific targets noted an attribute that can be measured (e.g. weed cover), these were often referred to as 'comparable' or 'agreed' levels. Out of all targets examined, only one-in-five provided a defined threshold, all of which were post-2006. Examples of defined thresholds includes:

- "Species diversity is not less than 60 percent of the known original species diversity" (Minister for Environment 2009a).

- "The abundance of weeds shall be no greater than the abundance of weeds in comparable nearby areas of land which have not been disturbed during implementation of the proposal" (Minister for Environment 2009b).

In terms of risk-management, only eight condition targets were found to mention any sort of monitoring or management of rehabilitation until affected areas are self-sustaining. All of these were defined between 2007 and 2009. Similarly, between 2008 and 2011, 15 targets included a time-bound specification such as "Species diversity not less than 70 percent of the known original species diversity within three years following the cessation of productive mining" (Minister for Environment 2009c).

\subsection{Post-mine land use}

Despite 16 MSs specifying that rehabilitation should be consistent or suitable for new agreed post-mining land uses, none of those actually stated the proposed post-mine land use in the MS.

Only $18 \mathrm{MS}$ in our dataset identified the anticipated post-mine land use for the site. These land uses were agriculture and native vegetation (nine times), pastoral use (four times), national park or state forest (three times), conservation and recreation (once), and water production (once).

To obtain information about proposed post-mine land uses for each project, one would need to find each project's mine closure plan. This proved to be a challenging exercise because mine closure plans are not typically publicly available on company websites, particularly for projects that started before 2011 . Since 2015, some approved mine closure plans are available for viewing through the DMIRS' mine and mineral deposits database (MINEDEX) query system (DMIRS n.d.-b). However, this database is not easily searchable and does not make all approved mine closure plans available. 
Instead of trying to ascertain proposed PMLU for every project listed in our dataset, we drew a random sample of sites by selecting the first MS every two years from 1987-2005 and then the first MS per year from 2006 onwards. For these 23 projects, we searched the companies' websites, MINEDEX, and the EPA websites for further information to assess whether the proposed PMLU has changed over time.

Of the 23 projects assessed in detail, information about proposed PMLU was only found for 12 of them. Information about PMLU was difficult to find and often hidden in the text of a proposed mine closure plan, EPA assessment reports, or Public Environmental Review documents for a project. The PMLUs specified included agriculture/pastoral use (seven times), native vegetation/conservation (seven times), restricted access/safety exclusion zone (twice), and recreation (once). Five projects proposed returning the land to multiple land uses, consistent with the pre-mining land use. As expected, projects in the Pilbara (or Goldfields) largely proposed low-intensity grazing and pastoral use, while projects in the southwest, Peel, and Perth areas focussed more on native vegetation. There was no pattern in changing definitions of PMLU over time. More relevant is the fact that mine closure plans could only be found for proposals after 2013, and PMLU was typically only defined in these mine closure plans, rather than in any other available project documentation. The full text of proposed PMLU and data sources are available in Appendix 2.

As part of assessing the status of rehabilitation in WA, this project also attempted to quantify the extent to which mined land has been rehabilitated. Some information on the level of disturbance can be found in reports that proponents have to submit annually to the Mining Rehabilitation Fund (MRF). In 2017-2018, a total of 164,824 ha of disturbance was reported across all licences (DMIRS 2018c). Of this, 38,627 ha of land (23.4\%) were under rehabilitation. For mining leases specifically, 135,159 ha of disturbed land were reported in $2017-2018$, of which $27 \%$ or 36,482 ha were under rehabilitation. The MRF reporting does not specify to what extent proponents are working towards meeting closure objectives and no progress towards meeting rehabilitation targets is available from these reports. As an aside, it may be challenging for members of the public to assess rehabilitation progress for a specific project because each project is reported under their tenement identifications, reducing the transparency of the system.

Finally, we attempted to document the cost of meeting rehabilitation conditions, however, very few cost estimates are publicly available. The MRF specifies the contribution levies for different types of land disturbances which, in principle, should cover the average expected costs of rehabilitation (Government of Western Australia 2013). These are, however, extremely broad categories that do not distinguish between rehabilitation conditions. A review of mining projects' annual environmental reports (DMIRS n.d.-a) revealed no information about rehabilitation costs other than the infrequent listing of the mine's total rehabilitation bond. For the 23 projects listed in Appendix 2, an extensive search for cost information yielded data for only four mines and in all cases without any detail of how the costs relate to rehabilitation actions or outcomes. None provided details on the rehabilitation activities, domains, or reference to rehabilitation conditions/targets.

\section{Conclusion}

This project is collecting the publicly available information about rehabilitation and/or closure conditions recommended by the EPA, aiming to document a long-term history of rehabilitation and/or closure conditions for mining projects in WA. The focus of this work has been on rehabilitation conditions related to ecological restoration and the 'land' factors assessed by the EPA.

Of the 277 mining and resource sector projects that were assessed by the EPA between 1987 and 2018, 236 (85\%) have had rehabilitation or closure conditions recommended and subsequently applied by the Minister for Environment through a MS. Since 2013 (following changes in the Mining Act), the proportion of MS with rehabilitation conditions has decreased, most likely transferring definitions of rehabilitation targets from MSs to mine closure plans instead. Most rehabilitation conditions were associated with preparing a decommissioning, closure, and/or rehabilitation plan, without specifying any condition targets or rehabilitation outcomes. Limited trends were observed in recommended rehabilitation conditions over time, between regions, or between projects of different sizes. 
A clear time trend is, however, visible when assessing condition targets (where specified in the MS). During the 1990s and early 2000s, condition targets were general in nature, and based on broad terms such as 'vegetation' or 'rehabilitation'. Over the last 10 years, condition targets have become more specific, with a few incorporating numeric thresholds.

A challenge in completing this project is the lack in readily accessible databases where information about rehabilitation is available. Rehabilitation conditions may be specified in MSs, but are not defined in a systematic, consistent way. PMLUs are not typically identified, which makes it impossible to evaluate whether targets support the agreed outcomes and land uses. The costs of meeting rehabilitation targets are hardly every reported, complicating any analysis of the feasibility of rehabilitation conditions and also adding to a lack of foresight and planning of funds needed for successful rehabilitation. Progress is being made to increase the transparency of information and decision-making around mine proposals and mine closure planning, particularly with publication of data on the EPA and DMIRS websites (EPA n.d.; DMIRS n.d.-a, n.d.b). However, the information needed to search these databases is not always easily accessible (registration title, tenement name, project name) and combined figures for WA regions are still unavailable. The current project hopes to improve the information availability by creating a database of rehabilitation conditions and targets for projects assessed by the EPA. Further work will be needed to

- Evaluate the economic achievability of rehabilitation conditions set by the regulators.

- Collate knowledge gained from trials and onsite research on the biophysical and ecological feasibility of rehabilitation targets.

- Collect evidence that enables an evaluation of rehabilitation towards targets set by regulators and proponents in their mine closure plans.

\section{Acknowledgement}

This work was commissioned by the Western Australian Biodiversity Science Institute (WABSI). Funding for this project was received from WABSI and the Department of Water and Environmental Regulation Environmental Protection Authority. Marit Kragt was funded by the Australian Government as an Australian Research Council Discover Early Career Award (DE160101306). 


\section{Appendix 1 Descriptive statistics for the database of ministerial} statements used in this study

\begin{tabular}{|c|c|}
\hline Variable & Sample characteristics \\
\hline Number of ministerial statements (MS) assessed & 277 \\
\hline Date range & $15 / 10 / 1987-28 / 12 / 2018$ \\
\hline \multicolumn{2}{|l|}{ Project types } \\
\hline Gas production - construction & 5 \\
\hline Gas production - infrastructure & 6 \\
\hline Mining - construction & 223 \\
\hline Mining - infrastructure & 18 \\
\hline Infrastructure development (general) & 22 \\
\hline Oilfield development & 3 \\
\hline \multicolumn{2}{|l|}{ Resource types } \\
\hline Aggregates (gravel, hard rock, and clay) & 8 \\
\hline Bauxite & 5 \\
\hline Clay & 8 \\
\hline Diamonds & 7 \\
\hline Gas & 14 \\
\hline Gold & 24 \\
\hline Iron ore & 114 \\
\hline Mineral sands & 43 \\
\hline Nickel & 12 \\
\hline Oil & 3 \\
\hline Rare earth minerals & 5 \\
\hline Salt & 5 \\
\hline Uranium & 5 \\
\hline $\begin{array}{l}\text { Others (coal, copper, granite, gypsum, lead, limestone, } \\
\text { molybdenum, silica, titanium, vanadium) }\end{array}$ & 20 \\
\hline \multicolumn{2}{|l|}{ Region } \\
\hline Gascoyne & 4 \\
\hline Goldfields-Esperance & 33 \\
\hline Great Southern & 5 \\
\hline Kimberley & 12 \\
\hline Mid-West & 29 \\
\hline Peel & 13 \\
\hline Perth & 26 \\
\hline Pilbara & 114 \\
\hline Southwest & 25 \\
\hline Wheatbelt & 16 \\
\hline Terrestrial footprint cleared (range in ha) & $4-26,925$ \\
\hline \# of MS with post-mine land use specified & 18 \\
\hline \# of MS with condition targets specified & 97 \\
\hline
\end{tabular}




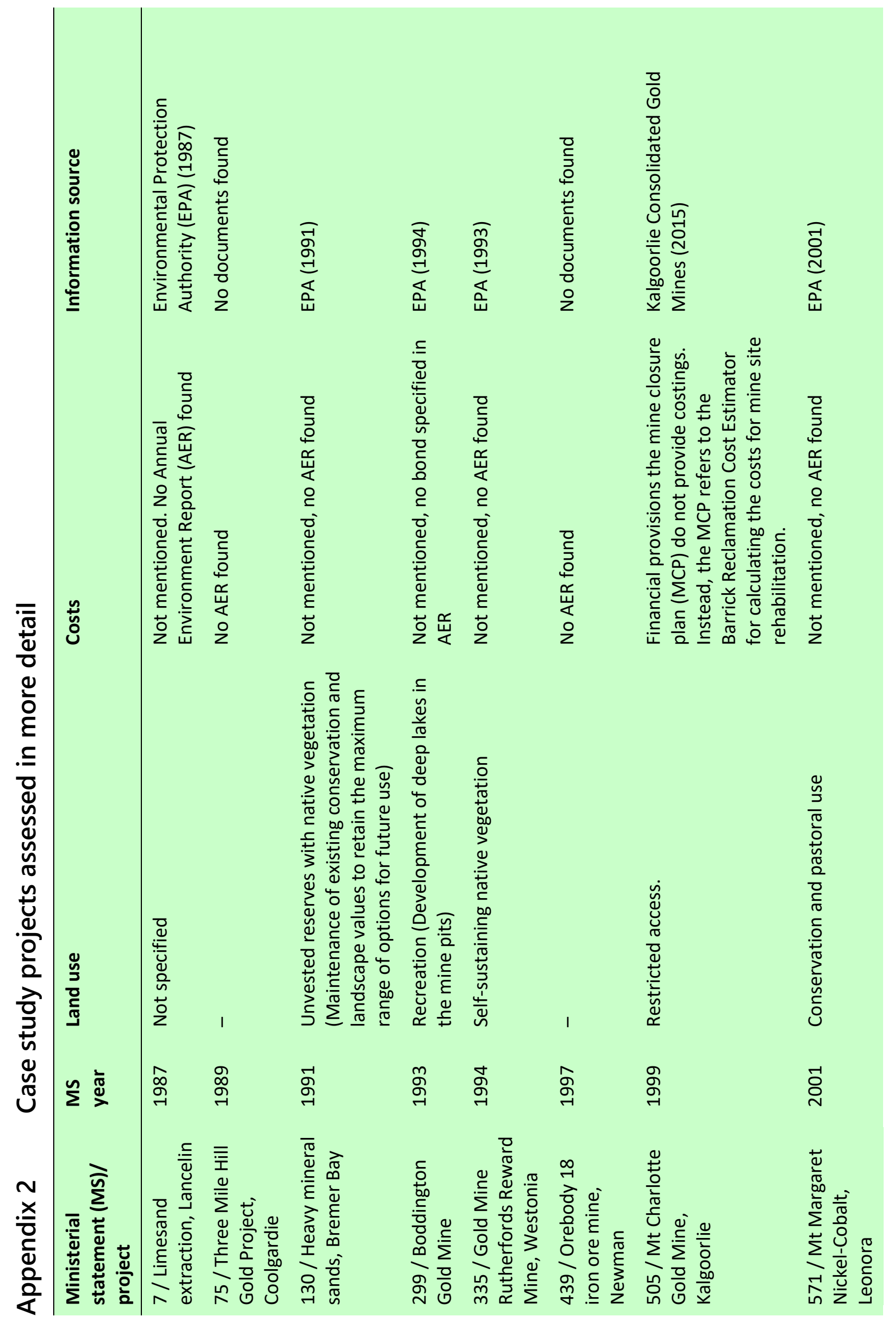




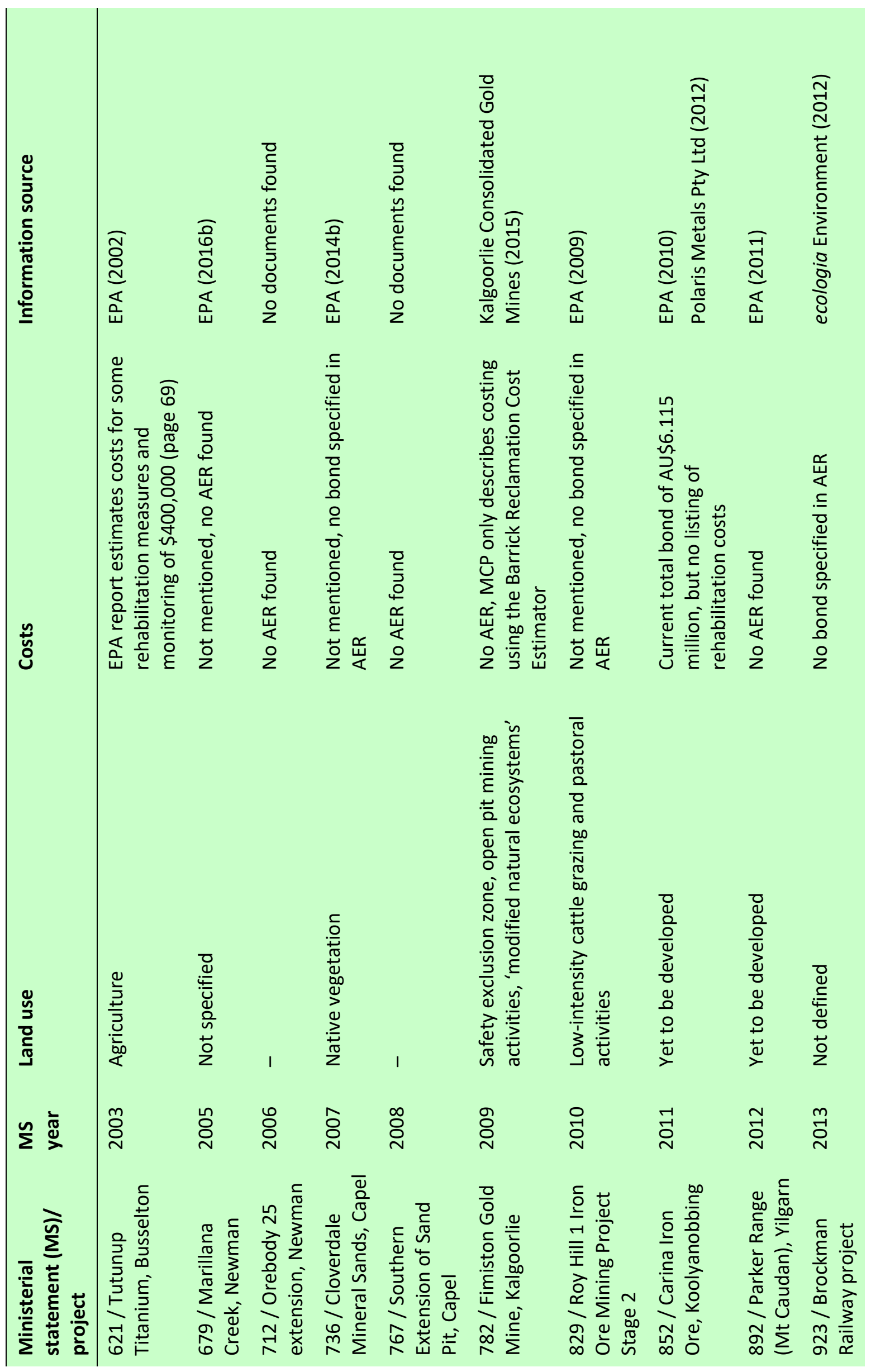




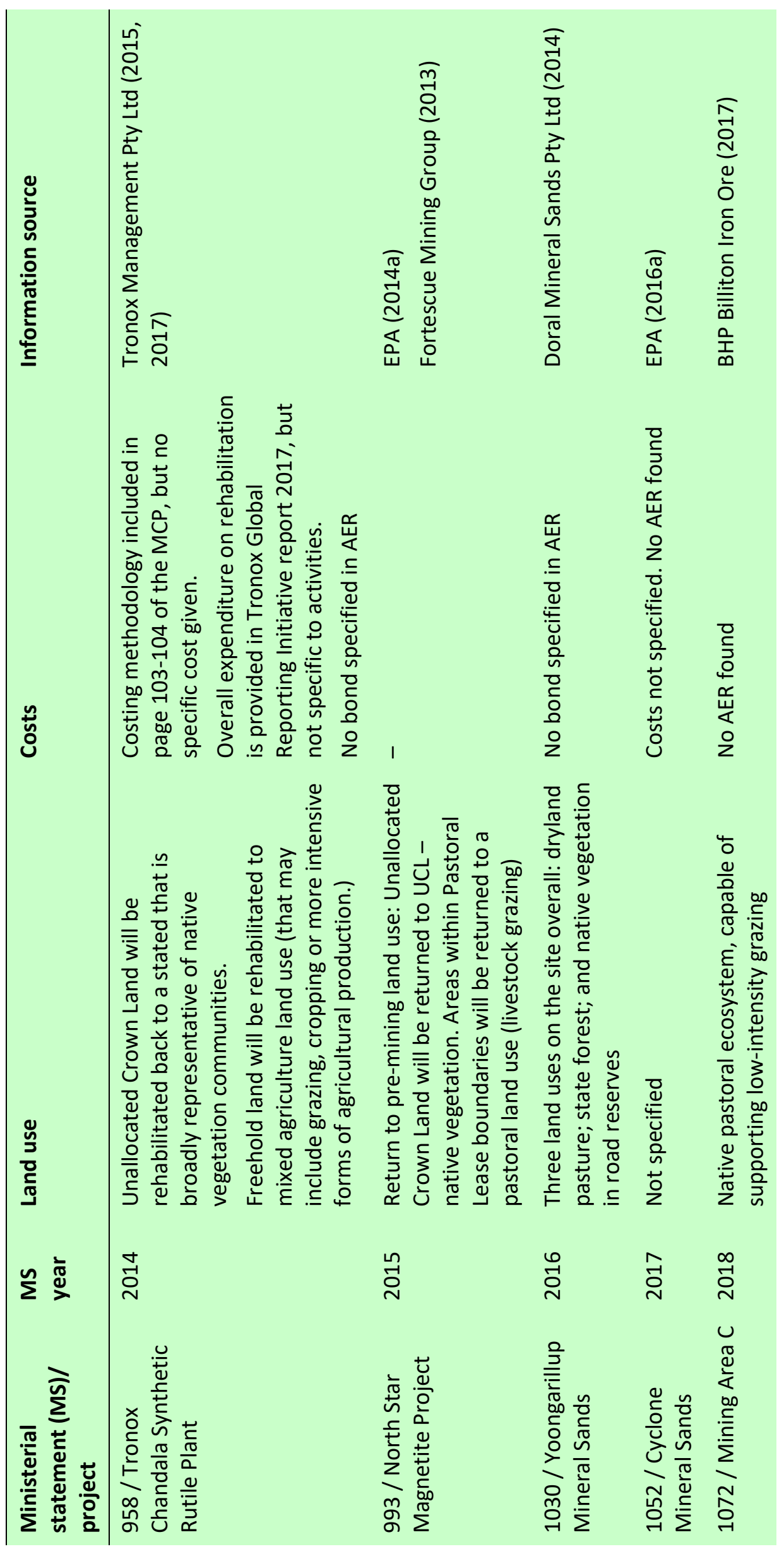




\section{References}

Australia and New Zealand Minerals and Energy Council \& Minerals Council of Australia 2000, Strategic Framework for Mine Closure, Canberra, http://www.sernageomin.cl/wp-content/uploads/2017/11/Strategic-Framework-Mine-Closure.pdf

BHP Billiton Iron Ore 2017, Mining Area C Mine Closure Plan, AML7000281, Revision 3.1, BHP Billiton Iron Ore, Perth, Western Australia

Department of Mines, Industry Regulation \& Safety n.d.-a, Environmental Assessment and Regulatory System, Government of Western Australia, http://www.dmp.wa.gov.au/Environmental-Assessment-and-1471.aspx

Department of Mines, Industry Regulation \& Safety n.d.-b, Mines and minerals deposits (MINEDEX), Government of Western Australia, http://www.dmp.wa.gov.au/Mines-and-mineral-deposits-1502.aspx

Department of Mines, Industry Regulation \& Safety 2018a, 2018 review of mineral and petroleum industry activity, Government of Western Australia, viewed 22 March 2019, http://dmp.wa.gov.au/About-Us-Careers/Latest-Resources-Investment4083.aspx

Department of Mines, Industry Regulation \& Safety 2018b, Mineral and petroleum commodity review 2018, Government of Western Australia, viewed 22 March 2019, http://www.dmp.wa.gov.au/About-Us-Careers/Latest-Statistics-Release-4081.aspx

Department of Mines, Industry Regulation \& Safety 2018c, Mining Rehabilitation Fund (MRF) 2018 Data Release, Government of Western Australia, http://www.dmp.wa.gov.au/Environment/What-is-the-MRF-19522.aspx

Department of Mines and Petroleum \& Environmental Protection Authority 2015, Guidelines for Preparing Mine Closure Plans. May 2015, Government of Western Australia, http://www.dmp.wa.gov.au/Documents/Environment/ENV-MEB-121.pdf

Doral Mineral Sands Pty Ltd, 2014, Yoongarillup Mineral Sands Project Preliminary Mine Closure Plan, M70/458 and M70/459, Commercial Information Removed, Doral Mineral Sands Pty Ltd, Perth.

ecologia Environment 2012, Brockman Iron Pty Ltd Rail Infrastructure Project Offset Plan, ecologia Environment, Perth.

Environmental Protection Authority n.d., Ministerial Statements, Government of Western Australia, http://www.epa.wa.gov.au/allministerial-statements

Environmental Protection Authority 1987, Limesand Extraction - Lancelin, Endeavour Resources Limited, Bulletin No. 294, Report and Recommendations of the Environmental Protection Authority, Perth, Western Australia

Environmental Protection Authority 1991, Heavy mineral sands exploration, Bremer Bay, Placer Pacific Ltd and Eucla Mining N/L, Bulletin No. 494, Report and Recommendations of the Environmental Protection Authority, Perth.

Environmental Protection Authority 1993, Proposed gold mine in 'C' Class Nature Reserve 18584 (Rutherford's Reward), Westonia, Rutherford Resources Pty Ltd, Bulletin No. 712, Report and Recommendations of the Environmental Protection Authority, Perth.

Environmental Protection Authority 1994, Boddington Gold Mine: Rehabilitation strategy, Worsley Alumina Pty Ltd, Bulletin No. 766, Report and Recommendations of the Environmental Protection Authority, Perth, Western Australia

Environmental Protection Authority 2001, Mt Margaret Nickel-Cobalt Project, Anaconda Nickel Limited, Bulletin No. 1025, Report and Recommendations of the Environmental Protection Authority, Perth, Western Australia

Environmental Protection Authority 2002, Tutunup Titanium Minerals Mine, Cable Sands (WA) Pty Ltd, Bulletin No. 1085, Report and Recommendations of the Environmental Protection Authority, Perth, Western Australia

Environmental Protection Authority 2009, Roy Hill 1 Iron Ore Mining Project, Stage 2, Roy Hill Iron Ore Pty Ltd, Report 1345, Report and Recommendations of the Environmental Protection Authority, Perth, Western Australia

Environmental Protection Authority 2010, Carina Iron Ore Project, Polaris Metals Pty Ltd, Report 1368, Report and Recommendations of the Environmental Protection Authority, Perth, Western Australia

Environmental Protection Authority 2011, Parker Range (Mount Caudan) Iron Ore Project, Cazaly Iron Pty Ltd, Report 1410, Report and Recommendations of the Environmental Protection Authority, Perth, Western Australia

Environmental Protection Authority 2014a, North Star Magnetite Project, Fortescue Metals Group Iron Bridge (Aus) Pty Ltd, Report 1514, Report and Recommendations of the Environmental Protection Authority, Perth, Western Australia

Environmental Protection Authority 2014b, Southern extension of sandpit, Calinup Road, Gelorup, Shire of Capel - inquiry under s46 of the Environmental Protection Act 1986 to amend Ministerial Statement 767, Cotton Holdings Pty Ltd, Report 1507, Report and Recommendations of the Environmental Protection Authority, Perth, Western Australia

Environmental Protection Authority 2016a, Cyclone Mineral Sands Project, Lost Sands Pty Ltd, Report 1575, Report and Recommendations of the Environmental Protection Authority, Perth, Western Australia

Environmental Protection Authority 2016b, Marillana Creek (Yandi) life-of-mine proposal - inquiry under section 46 of the Environmental Protection Act 1986 to amend Ministerial Statement 679, BHP Billiton Iron Ore Pty Ltd, Report 1577, Report and Recommendations of the Environmental Protection Authority, Perth, Western Australia

Environmental Protection Authority 2018a, Environmental Impact Assessment (Part IV Divisions 1 and 2) Procedures Manual, Government of Western Australia, http://www.epa.wa.gov.au/sites/default/files/Policies_and_Guidance/EIA\%20 Procedures\%20Manual\%20300418.pdf

Environmental Protection Authority 2018b, Statement of Environmental Principles, Factors and Objectives, Government of Western Australia, http://epa.wa.gov.au/sites/default/files/Policies_and_Guidance/Statement\%20of\%20Environmental\%20 Principles\%2C\%20factors\%20and\%20objectives_29062018_0.pdf

Fortescue Mining Group 2013, North Star Magnetite Project Public Environmental Review, Fortescue Mining Group, Perth.

Government of Western Australia 1978, Mining Act 1978, Australia.

Government of Western Australia 1986, Environmental Protection Act 1986, Australia.

Government of Western Australia 2013, Mining Rehabilitation Fund Regulation 2013, Australia. 
Minister for Environment 2009a, Devil Creek Development Project, Gnoorea Point, Shire of Roebourne, Statement No. 795, Government of Western Australia, http://www.epa.wa.gov.au/sites/default/files/Ministerial_Statement/00795\%282\%29.PDF

Kalgoorlie Consolidated Gold Mines, 2015, Mine Closure Plan, Kalgoorlie Consolidated Gold Mines, Kalgoorlie.

Minister for Environment 2009b, Chichester Rail Deviation, Shire of Ashburton, Statement No. 818, Government of Western Australia, http://www.epa.wa.gov.au/sites/default/files/1MINSTAT/00818.PDF

Minister for Environment 2009c, Tutunup South Mineral Sands Project, Statement No. 799, Government of Western Australia, http://www.epa.wa.gov.au/sites/default/files/Ministerial_Statement/00799_0.pdf

Minister for the Environment 2006, Phillips River Gold Project, Shire of Ravensthorpe, Statement No. 716, Government of Western Australia, http://epa.wa.gov.au/sites/default/files/1MINSTAT/000716.pdf

Minister for the Environment 2005, Yandicoogina Junction South-East Mine, Mining Lease 274SA, Shire of East Pilbara, Statement No. 695, Government of Western Australia, http://www.epa.wa.gov.au/sites/default/files/1MINSTAT/000695.pdf

Minister for the Environment 2000a, Mineral Sands Mining and Rubbish Tip Relocation Reserve 31900, Yarloop, Shire of Harvey, Statement No. 550, Government of Western Australia, http://epa.wa.gov.au/sites/default/files/1MINSTAT/000550.pdf

Minister for the Environment 2000b, Magellan Lead Carbonate Project, Wiluna, Statement No. 559, Government of Western Australia, http://www.epa.wa.gov.au/sites/default/files/Ministerial_Statement/000559_0.pdf

Minister for Environment 1988, Yandicoogina (Marillana) Iron Ore Project, Marillana Station, Statement No. 29, Government of Western Australia, http://epa.wa.gov.au/sites/default/files/1MINSTAT/000029.pdf

Polaris Metals Pty Ltd 2012, Mining Proposal, Carina Extended Iron Ore Project, M77/1261 and M77/1244, Yilgarn Region WA, Polaris Metals Pty Ltd, Perth.

Tronox Management Pty Ltd 2015, Cooljarloo Mine including Cooljarloo West: Mine Closure Plan, Tronox Management Pty Ltd, Dandaragan.

Tronox Management Pty Ltd 2017, Cooljarloo West Titanium Minerals Project: Public Environmental Review, EPA Assessment No. 1974, Tronox Management Pty Ltd, Muchea. 